\title{
Frequency of micronuclei and of other nuclear abnormalities in erythrocytes of the grey mullet from the Mondego, Douro and Ave estuaries-Portugal
}

\author{
João Carrola • Nádia Santos • Maria J. Rocha • \\ António Fontainhas-Fernandes • Miguel A. Pardal • \\ Rogério A. F. Monteiro • Eduardo Rocha
}

Received: 30 March 2013 / Accepted: 8 January 2014 / Published online: 28 January 2014

(C) Springer-Verlag Berlin Heidelberg 2014

\begin{abstract}
Fish are bioindicators of water pollution, and an increased rate of their erythrocyte nuclear morphological abnormalities (ENMAs) - and particularly of erythrocyte micronuclei (EMN) - is used as a genotoxicity biomarker. Despite the potential value of ENMAs and $\mathrm{MN}$, there is scarce information about fish captured in Iberian estuaries. This is the case of the Portuguese estuaries of the Mondego, Douro and Ave, suffering from different levels of environmental stress and where chemical surveys have been disclosing significant
\end{abstract}

Responsible editor: Philippe Garrigues

J. Carrola $\cdot$ A. Fontainhas-Fernandes

UTAD - University of Trás-os-Montes e Alto Douro,

ECVA - School of Life and Environmental Sciences,

CITAB - Centre for the Research and Technology of

Agro-Environmental and Biological Sciences, Quinta de Prados,

Apartado 1013, 5001-801 Vila Real, Portugal

N. Santos $\cdot$ M. J. Rocha $\cdot$ R. A. F. Monteiro $・$ E. Rocha $(\bowtie)$

Laboratory of Histology and Embryology, Department of

Microscopy, Institute of Biomedical Sciences Abel Salazar (ICBAS),

University of Porto (UPorto), Rua de Jorge Viterbo Ferreira n. 228,

4050-313 Porto, Portugal

e-mail: erocha@icbas.up.pt

\section{J. Rocha}

Department of Pharmaceutical Sciences, Superior Institute of Health Sciences-North (ISCS-N), CESPU, Rua Central de Gandra 1317, 4585-116 Gandra, Paredes, Portugal

\section{J. Rocha $\cdot$ R. A. F. Monteiro $\cdot$ E. Rocha}

Laboratory of Cellular, Molecular and Analytical Studies, Interdisciplinary Center of Marine and Environmental Research (CIIMAR), CIMAR Associated Laboratory (CIMAR LA), University of Porto (UPorto), Rua dos Bragas, 289, 4050-123 Porto, Portugal

M. A. Pardal

Centre for Functional Ecology, Department of Life Sciences,

University of Coimbra, Apartado 3046, 3001-401 Coimbra, Portugal amounts of certain pollutants. So, the aim of this study was to evaluate genotoxicants impacts and infer about the exposure at those ecosystems, using the grey mullet (Mugil cephalus) as bioindicator and considering the type and frequency of nuclear abnormalities of erythrocytes as proxies of genotoxicity. Sampling of mullets was done throughout the year in the important Mondego, Douro and Ave River estuaries (centre and north-western Portugal). The fish (total $n=242$ ) were caught in campaigns made in spring-summer and autumnwinter, using nets or fishing rods. The sampled mullets were comparable between locations in terms of the basic biometric parameters. Blood smears were stained with Diff-Quik to assess the frequencies of six types of ENMAs and MN (given per 1,000 erythrocytes). Some basic water physicochemical parameters were recorded to search for fluctuations matching the ENMAs. Overall, the most frequent nucleus abnormality was the polymorphic type, sequentially followed by the blebbed/ lobed/notched, segmented, kidney shaped, vacuolated, MN and binucleated. The total average frequency of the ENMAs ranged from $73 \%$ in the Mondego to $108 \%$ in the Ave. The polymorphic type was typically $\geq 50 \%$ of the total ENMAs, averaging about $51 \%$, when considering all three estuaries. The most serious lesion - the MN-in fish from Mondego and Douro had a similar frequency $(\approx 0.38 \%$ ), which was significantly lower than that in the Ave $(0.75 \%$ ). No significant seasonal differences existed as to the $\mathrm{MN}$ rates and seasonal differences existed almost only in the Douro, with the higher values in AW. In general, the pattern of ENMAs frequencies was unrelated with the water physicochemical parameters. Considering the data for both the total ENMAs and for each specific abnormality, and bearing in mind that values of $\mathrm{MN}$ in fish erythrocytes $>0.3 \%$ usually reflect pollution by genotoxicants, it is suggested that mullets were likely being chronically exposed to such compounds, even in the allegedly less polluted ecosystem (Mondego). Moreover, data supported the following pollution 
exposure gradient: Mondego $<$ Douro $<$ Ave. The scenario and inferences nicely agree with the published data from chemical monitoring.

Keywords Fish $\cdot$ Blood $\cdot$ Erythrocytes $\cdot$ Micronuclei · Toxicology $\cdot$ Biomarkers

\section{Introduction}

Pollution by genotoxicants is particularly dangerous in view of their grave effects, such as enhancing of carcinogenesis, generation of hereditary defects via germ-cell mutations or induction of embryotoxicity, with adverse consequences ranging from individuals to populations, with ecological costs (Mitchelmore and Chipman 1998). Fish are important indicators of water pollution and the emergence/rate of erythrocytes nuclear morphological abnormalities (ENMAs), including the erythrocytes micronuclei (MN), are being used to examine both the exposure and effect of mutagenic compounds. Indeed, the formation of $\mathrm{MN}$ in fish has been increasingly used, in field and laboratorial studies, to detect both the genotoxic potential of pollutants and as an indicator of chromosomal injury (Al-Sabti and Hardig 1990; Al-Sabti and Metcalfe 1995; Baršienė et al. 2012; Bolognesi et al. 2006; Buschini et al. 2004; Cavalcante et al. 2008; De Flora et al. 1993; Hooftman and de Raat 1982; Hose et al. 1987; Minissi et al. 1996; Rocha et al. 2009; Vigano et al. 2002; Winter et al. 2007). Besides, if by the one hand the appearance of $M N$ in fish is valuable in ecological risk assessment - even able to disclose the risk of human exposure to drinking water with genotoxicants - on the other hand, the affected fish also pose risks, as feeding is well established as a major toxicant exposure route in human populations (Oates and Cohen 2009; Tijhuis et al. 2012).

In teleost fish, normal erythrocytes are generally oval, bearing an elliptic nucleus. Changes in the nuclei morphology are good indicators of exposure to genotoxic chemicals in the wild, being also used experimentally in initial evaluations of clastogenic potential; namely via the erythrocyte micronucleus test. The practical determination of MN frequency is a simple and cheap process, despite being time-consuming, particularly when conducted on a large field samples. MN frequency in blood cells is also used in humans to assess the exposure to genotoxic compounds, as illustrated in a study in which greenhouse workers exposed to pesticides increased their MN frequency (Costa et al. 2007). Moreover, it is known for long that the MN analysis in erythrocytes shows the general impact of genotoxicants occurring during the period of erythrocyte development and circulation (Schlegel and MacGregor 1982).

Significant ecotoxicological insights are gained from analysing MN. For instance, in Amazonian fish (Porto et al.
2005) it was observed that piscivore species presented almost five-fold higher $\mathrm{MN}$ rate than the detritivorous/omnivorous species. So, the MN were useful in disclosing differential exposure/effects, in addition to allowing correlations between genotoxicity and mercury pollution. Another nice example came from da Silva-Sousa and Fontanetti (2006), who used $\mathrm{MN}$ and nuclear alterations on erythrocytes of Nile tilapia (Oreochromis niloticus) to infer about the water quality status of a Brazilian river; in accordance with the biomarkers, substances with clastogenic/aneugenic and cytotoxic potential were found, mainly at the point matching the drainage of oil shale plant wastes. More recently, Arslan et al. (2010) monitored the Turkish Izmir bay and found that the frequency of $\mathrm{MN}$ in a goby fish (Gobius niger) was higher in those locations highly impacted by wastes from dockyards. The three above exemplificative studies skilfully emphasize that, overall, there has been a consistent positive relation between water pollution and $\mathrm{MN}$, as several field and laboratory studies done with teleosts showed a higher prevalence of $\mathrm{MN}$ after exposure to environmental pollution or to different chemicals under controlled conditions (Minissi et al. 1996; Da Rocha et al. 2009). However, this is not always true. For example, Carrasco et al. (1990) found no steady correlation between abnormal variations of the erythrocyte nuclear morphology and neither (1) the measured levels of contaminants in sediments and in bile or liver of the white croaker (Genyonemus lineatus), nor (2) the prevalence of idiopathic liver lesions. Also relevant here is that variability in $\mathrm{MN}$ frequency exists in different studies, even with humans (Speit and Schmid 2006). So, there are inter and intraindividual variances when assessing the frequency of MN and of other nuclear anomalies, and thus there is a potential for misclassification and a need for adequate sampling. Despite limitations, at least the $\mathrm{MN}$ are well established indicators of genotoxicity in fish (Cavas et al. 2005; Da Rocha et al. 2009).

In parallel to the $\mathrm{MN}$, other ENMAs are often noted in fish subjected to environmental pollution or experimentally exposed to genotoxic/cytotoxic chemicals (Ayllón and Garcia-Vazquez 2001; Barsiene et al. 2006; Çavas and Ergene-Gözükara 2005a). In wild fish, the quantification of ENMAs was proved useful to understand the type/intensity of chemical impacts in health (Rodriguez-Cea et al. 2003). Those abnormalities are also regarded as indicators of cytotoxic/genotoxic damage in fish and, therefore, they are viewed as useful complements to MN scoring in genotoxicity surveys (Çavas and ErgeneGözükara 2005b). However, authors have been using diverse classifications for the ENMAs. For example, whereas Carrasco et al. (1990) described the abnormal nuclei as being blebbed, notched or lobed, other authors reported nuclear abnormalities grouping them into the single category of 'genotoxic damage' (Ayllon and Garcia-Vazquez 2000; Pacheco and Santos 1999). Strunjak-Perovic et al. (2009) used a scoring system for ENMAs as advised by Carrasco et al. (1990), but blebbed, 
lobed and notched nuclei were interpreted together and named 'irregularly shaped nuclei' (ISN); vacuolated nuclei (VN), binucleated cells/binuclei $(\mathrm{BN})$ and micronuclei $(\mathrm{MN})$ were classified separately — the various strategies complicate comparisons.

Despite the potential value of the study of both ENMAs and $\mathrm{MN}$, there is not much data available for fish in Portuguese estuaries. However, the presence and effects of genotoxic pollutants cannot be discarded, and it is likely to occur, namely facing reports of pollution by different classes of chemicals. This is the case of the estuaries Mondego, Douro and Ave rivers, in Portugal, where chemical surveys have been systematically disclosing significant amounts of pollutants of various classes, often within biologically hazardous ranges (Carvalho et al. 2009; Díez et al. 2005; Madureira et al. 2009, 2010; Ramalhosa et al. 2005; Ribeiro et al. 2009a, b; Rocha et al. 2011, 2012a, b, 2013a, b). Taking all into consideration, we suspected that fish living in those estuaries faced different levels of stress, and could be differently impacted by genotoxicity. Among the fish in those estuaries, mullets are prevalent; being well suited for biomonitoring (Whitfield et al. 2012). So, this study was made to evaluate genotoxicant exposure via damage impact assessment, using the grey mullet as bioindicator and regarding the nuclear abnormalities of erythrocytes as proxies of the genotoxicity. Our specific aims were to: (1) characterize the morphological types and frequencies of ENMAs; including (2) assess the frequency of $\mathrm{MN}$; and (3) infer about the possibility of exposure to genotoxicants in the three estuaries.

\section{Materials and methods}

\section{Biology of the bioindicator species}

The grey mullet (M. cephalus) is the most widespread species among the family Mugilidae, but almost nothing specific is published about the biology of this fish in Portugal, and so we must rely on general sources of information for the species; namely as it is present in the coastal waters of most tropical and subtropical zones. The species is catadromous and eurihyaline, being found coastally, particularly in estuaries but also in freshwater bodies; it is tolerant of a wide range of salinities. They spend most of their life in brackish and freshwater and are sexually mature after 3 to 4 years. Adults form schools at the surface, over sandy or muddy bottoms, and migrate offshore to spawn (autumn to winter). Evidences suggest that specimens spawn more than once in lifetime, do return to estuaries after spawning, and recaptures support that they home back to the same estuary and that they do not migrate in some years (spawning does not occur, and gametes are reabsorbed). Initially, the larvae migrate inshore to extremely shallow water, and later juveniles $(\approx 5 \mathrm{~cm})$ move into slightly deeper waters. Grey mullet is a diurnal feeder, mainly eating zooplankton, dead plant matter, and detritus. Feeding by sucking up the top layer of sediments, they remove both detritus and microalgae. They also pick up some sediment, which serves to grind food in the gizzard-like portion of their stomachs. Mullet also graze on epiphytes and epifauna from seagrasses as well as ingest surface scum carrying microalgae at the air-water interface. The above data and further aspects of the biology of the species are detailed elsewhere (Bartulović et al. 2011; Blaber 1976; Cardona 2006; CostaEiras and Carraca 1979; Oren 1981; Saleh 2006; Whitfield et al. 2012).

\section{Sampling area}

Capture and sampling of grey mullets was done in three important (centre- and north-western) Portuguese estuaries: Ave, Douro and Mondego (Fig. 1). As summarized by Rocha et al. (2013a), the Ave River is located in Northwest Portugal, running along intensive agricultural areas that drain large amounts of agrochemicals into the water bodies; it reaches the Atlantic Ocean at Vila do Conde city, housing about 28,600 habitants. Besides, the area is one of the most industrialized of the country, supporting many industries, namely textiles, metal plating, leather tanning, rubber and plastic, cutlery and metalworking; high levels of pollution was registered in the last decades. As summarized by Rocha et al. (2012a; 2013b), the Douro river is an international watercourse that originates in north-central Spain, runs along the Spanish-Portuguese border, and enters the Atlantic Ocean at the city of Porto. The latter area is densely inhabited, with more than 700,000 residents in the last $8 \mathrm{~km}$ of the estuary. This is the final "reservoir" of all the water that comes from the Douro basin, the biggest of the Iberian Peninsula, as well as from agriculture (especially of grape vines) located in Douro River margins. Due to climatic and soil conditions, agricultural practices in this region are strongly dependent of pesticides. As summarized by Ribeiro et al (2009a, b), the Mondego River flows from the Serra da Estrela mountain to the Atlantic Ocean, running through rural and importantly urbanized and industrialized areas before reaching its estuary. Its main pollution sources are effluents - most from sewage treatment plants giving support to about 200,000 inhabitants and to different types of industries - and agricultural run-offs, the end result of 15,000 ha of cultivated land (mostly rice and corn fields) located upstream the Mondego estuary; despite reported as less polluted than the two other estuaries, its pollution increased over the last decade. Despite this fact, there are zones in the estuary that are being used as references, for instance as to mercury pollution (Cardoso et al. 2009) 
Fig. 1 Geographic location of the three watersheds studied, in the centre and north of Portugal, namely the estuaries of the Mondego, Douro and Ave rivers

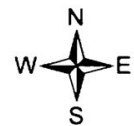

Watersed of the rivers:

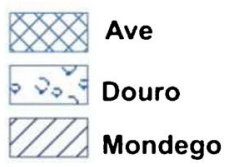

$100 \mathrm{Km}$
Fish collection

Fish were caught in campaigns made in two periods per year (on average, $n=42 /$ per period), in spring-summer (SS) and in autumn-winter (AW), using nets and fishing rods. Sampling was done in 2006 (Mondego), 2007 (Douro) and 2008 (Ave). Soon after being caught, the fish were immediately transported alive to in-house facilities where they were held alive in plastic tanks of $500 \mathrm{~L}(1.2 \times 1.0 \times 0.7 \mathrm{~m})$ supplied with continuously flowing brackish water, at flow rates of 2,000 L/ $\mathrm{h}$ and with both mechanical and biological filtration systems. The oxygen level was kept near saturation by continuous aeration. The dark/light photoperiod was adjusted to the season, in order to simulate the natural photoperiod. For logistic reasons, but maintaining comparability, sampling started only on the day following capture, and so each fish was held in the systems for up to $48 \mathrm{~h}$ before blood collection. This was performed immediately after euthanasia using a $200 \mathrm{mg} / \mathrm{L}$ overdose of tricaine methane sulfonate (MS-222, Sandoz). The procedures were equally standardized for all estuaries. During all fish handling processes, in the field and until sampling, the animal research ethics guidelines were respected considering national and European Union laws. Before necropsy each fish was weighed and measured, and thereafter inspected for external and internal gross lesions.

\section{Cytological technique and evaluation of ENMAs}

Blood samples were obtained by caudal venipuncture using heparinized syringes (with needles of different length and gauge, according to fish size). Then, the blood was immediately
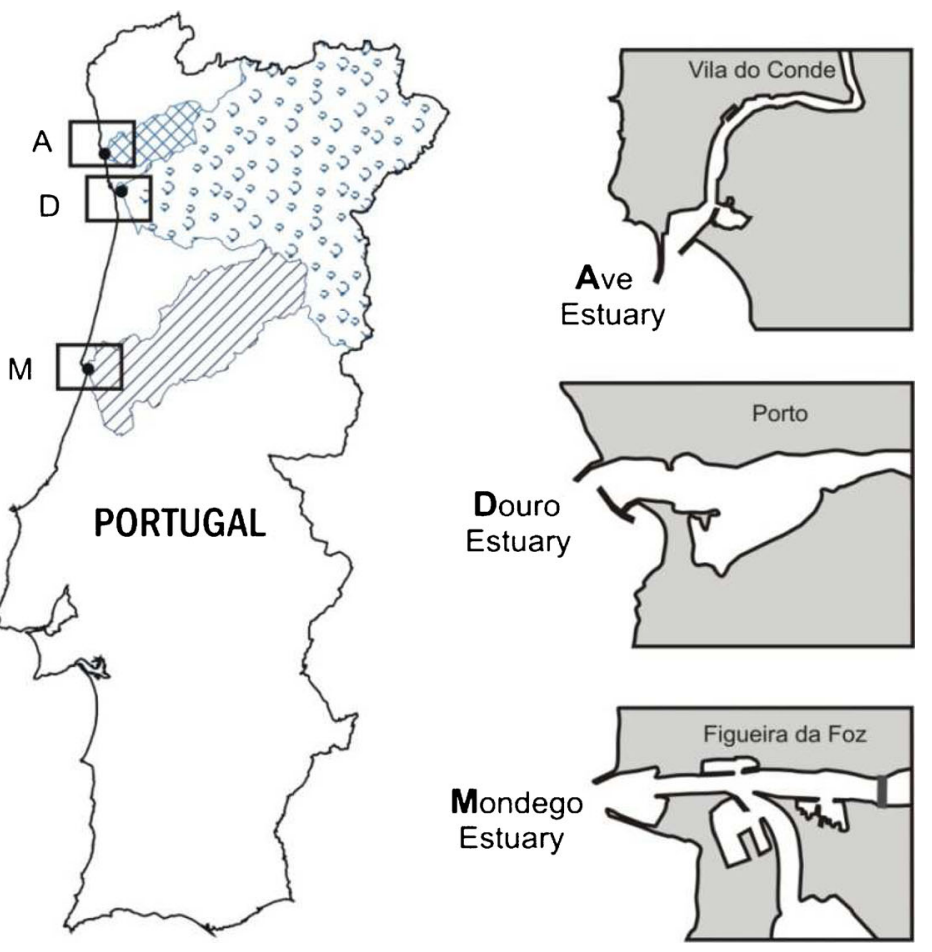

smeared on ethanol-washed slides and allowed to air dry, before fixation in absolute methanol for $10 \mathrm{~min}$, with two slides being prepared per fish. Slides were stained using the Diff-Quik procedure. From each fish, 150 fields of view were observed in live images displayed on a 22" LCD monitor (at final magnification of $\times 2,500$ ), captured with a high-quality Peltier cooled digital camera (DP71, Olympus), mounted on a microscope (IX71, Olympus) equipped with motorized stage and a PlanApo $\times 100$ oil immersion objective $(\mathrm{NA}=1.5)$. To unbiased sample the erythrocytes and avoid edge effects we used a square sampling grid with forbidden lines (Gundersen 1977), which occupied $30 \%$ of the displayed live image. At times, analysis was complemented by direct observation via the microscope eyepiece (final magnification $\times 1,000$ ). Around 1,000 to 1,700 cells were analysed per fish.

As to identification criteria, all the non-refractive, isolated, circular or ovoid chromatin bodies, smaller than one third of the main nucleus and displaying the same staining and focusing patterns of the latter, were scored as MN (Al-Sabti and Metcalfe 1995; Carrasco et al. 1990). ENMAs (including $\mathrm{MN})$ were sorted into six groups: (1) Polymorphic (PM)with irregular nuclei outlines and no consistent pattern; (2) Segmented (SM) - symmetrical or asymmetrical hourglass shaped nuclei; (3) Kidney shaped (KN) - nuclei with a kidney shaped profile; (4) Blebbed/lobed/notched (BLN)-blebbed nuclei had a relatively small evagination of the nuclear envelope, lobed nuclei were those presenting evaginations larger that the blebbed nuclei, a notched nucleus had an appreciable invagination. All three were grouped as BLN; (5) Binucleated 
(BN) - two nuclei with approximately equal sizes, but clearly separated; (6) Micronucleus (MN) — as defined above; (7) Vacuolated (VC) — nucleus with a vacuole (typically centrally located). The frequencies of each type ENMA were expressed per 1,000 erythrocytes (per mil). The sum of the frequencies of all types of abnormalities $(\mathrm{PM}+\mathrm{SM}+\mathrm{KN}+\mathrm{BLN}+\mathrm{BN}+\mathrm{MN}+$ VC) was also calculated per animal.

\section{Physicochemical parameters of the water}

Surface water samples were taken near the locations where fishes were captured, both at high and low tide. Several basic physicochemical parameters were quantified and grouped for this study as for the biological data, i.e. in sets of SS and AW, pooling all the relevant measurements. The temperature, $\mathrm{pH}$, dissolved oxygen, conductivity and salinity, were evaluated at the field locations, using a portable electrochemical analyzer (Hach Lange HQD-Electrochemistry Multi-meter). For carrying to the laboratory, the bottles with samples were stored at $\approx 5^{\circ} \mathrm{C}$. At the facilities, the amounts of nitrite, nitrate, total ammonia and phosphate were measured (in duplicate) using a Palintest 7000 Interface Photometer. The data served to see if there was any pattern that could be related with the ENMAs rates.

\section{Statistical analysis}

Data are given as mean followed by the standard error per fish group. The software Statistica 10 (StatSoft) was used to test comparisons of ENMAs rates. Data were analysed by one-way ANOVA followed by post hoc tests. Analyses were done either joining all seasonal data per estuary, or separating data sets per season. Normality and homogeneity of variance were checked, respectively with the Shapiro-Wilk $W$ test and the Levene test. There was no homogeneity of variances for the data grouped by seasons, and so the sets were analysed by the non-parametric Kruskal-Wallis test, followed by comparisons of mean ranks of all pairs of groups, conducted by the Siegel and Castellan post hoc test. When using data sets separated by season, analyses were made via the parametric one-way ANOVA, followed by the post hoc Newman-Keuls test. The standard significance level of $5 \%$ was adopted and so when we mention in the text that a difference was statistically significant this means that the null hypothesis was rejected and that $p<0.05$.

\section{Results}

Fish data

In the Mondego estuary, 39 animals were analysed in SS (body mass $(\mathrm{BM})=501.4 \pm 426.9 \mathrm{~g}$; total length $(\mathrm{TL})=35.6 \pm$ $10.0 \mathrm{~cm})$ and 52 in $\mathrm{AW}(\mathrm{BM}=454.8 \pm 225.9 \mathrm{~g} ; \mathrm{TL}=37.6 \pm$ $7.6 \mathrm{~cm})$; in Douro, 43 animals in SS $(\mathrm{BM}=381.0 \pm 124.6 \mathrm{~g}$; $\mathrm{TL}=37.2 \pm 4.9 \mathrm{~cm})$ and 34 in $\mathrm{AW}(\mathrm{BM}=430.2 \pm 108.3 \mathrm{~g}$; $\mathrm{TL}=$ $38.2 \pm 3.2 \mathrm{~cm})$; and in Ave, 39 animals in $\mathrm{SS}(\mathrm{BM}=456.5 \pm$ $186.6 \mathrm{~g} ; \mathrm{TL}=35.92 \pm 4.4 \mathrm{~cm})$ and 35 in $\mathrm{AW}(\mathrm{BM}=478.8 \pm$ $199.8 \mathrm{~g} ; \mathrm{TL}=37.8 \pm 4.7 \mathrm{~cm})$. The groups did not differ significantly $(p>0.05)$ in BM or in TL.

Frequencies of nuclear abnormalities

Data on the occurrence of ENMAs are summarized in Table 1 (seasons joined) and Table 2 (considering seasons separately), which include the summary of the statistical analyses by signalling all the significant differences. Data are presented per estuary and were not split by sex as males and females did not differ in ENMAs rates. Overall, the most frequent abnormality was the PM, sequentially followed by BLN, SM, KN, VC, MN and finally BN. The PM was typically $\geq 50 \%$ of the total ENMAs, averaging about 51 affected erythrocytes/1,000 counted erythrocytes, when considering all three estuaries. The most serious lesion, the MN, average among the three estuaries was 0.52 micronucleated cells/1,000 erythrocytes.

Looking at all lesions summed, the total ENMAs tended to increase from the Mondego towards the Ave. In the Douro and Ave, the ENMAs existed in about $10 \%$ of the erythrocytes. Accordingly, the statistical differences followed the trend, with the mullets from the Mondego displaying significantly lower total figures than those from Douro and, particularly, than those caught at the Ave. When we viewed the seasons separately, the same trend existed, with the Mondego displaying almost always lower frequencies than the Ave

Table 1 Frequencies of total and of specific erythrocytes nuclear morphological abnormalities (ENMAs) (n/1,000 erythrocytes) in mullets from the Mondego, Douro and Ave estuaries (data from seasons joined)

\begin{tabular}{|c|c|c|c|c|c|c|c|c|}
\hline & PM & SM & $\mathrm{KN}$ & BLN & $\mathrm{BN}$ & $\mathrm{MN}$ & $\mathrm{VC}$ & Total ENMAs \\
\hline Mondego & $43.24 \pm 3.41^{\mathrm{a}}$ & $11.67 \pm 1.30^{\mathrm{a}}$ & $4.00 \pm 0.25^{\mathrm{a}}$ & $14.06 \pm 0.70^{\mathrm{a}}$ & $0.02 \pm 0.01^{\mathrm{a}}$ & $0.41 \pm 0.07^{\mathrm{a}}$ & $0.58 \pm 0.07^{\mathrm{a}}$ & $73.29 \pm 4.59^{\mathrm{a}}$ \\
\hline Douro & $56.91 \pm 4.05^{\mathrm{b}}$ & $16.62 \pm 1.61^{\mathrm{b}}$ & $6.02 \pm 0.60^{\mathrm{a}}$ & $19.53 \pm 1.28^{\mathrm{b}}$ & $0.02 \pm 0.02^{\mathrm{a}}$ & $0.35 \pm 0.08^{\mathrm{a}}$ & $1.20 \pm 0.26^{\mathrm{a}}$ & $100.66 \pm 6.08^{b}$ \\
\hline Ave & $52.55 \pm 3.16^{\mathrm{b}}$ & $13.00 \pm 0.73^{\mathrm{b}}$ & $8.10 \pm 0.73^{\mathrm{b}}$ & $31.63 \pm 2.40^{\mathrm{c}}$ & $0.15 \pm 0.03^{\mathrm{b}}$ & $0.75 \pm 0.12^{\mathrm{b}}$ & $2.23 \pm 0.29^{\mathrm{b}}$ & $108.42 \pm 4.81^{b}$ \\
\hline
\end{tabular}

Data given as mean \pm standard error (Mondego $n=91$ fish; Douro $n=77$; Ave $n=74$ ). Values bearing different superscript letters differ significantly $(p<0.05)$

$P M$ polymorphic, $S M$ segmented, $K N$ kidney shaped; $B L N$ blebbed/lobed/notched, $B N$ binucleated, $M N$ micronucleus, $V C$ vacuolated 
Table 2 Frequencies of total and of specific erythrocytes nuclear morphological abnormalities (ENMAs) $(n / 1,000$ erythrocytes) in mullets from the Mondego, Douro and Ave estuaries, at each sampling season

\begin{tabular}{|c|c|c|c|c|c|c|c|c|}
\hline & PM & SM & $\mathrm{KN}$ & BLN & $\mathrm{BN}$ & $\mathrm{MN}$ & $\mathrm{VC}$ & Total ENMAs \\
\hline Mondego (SS) & $40.57 \pm 4.21^{\mathrm{a}}$ & $13.51 \pm 1.99^{\mathrm{ab}}$ & $4.03 \pm 0.41^{\mathrm{a}}$ & $13.96 \pm 1.10^{\mathrm{a}}$ & $0.03 \pm 0.03^{\mathrm{ab}}$ & $0.52 \pm 0.12^{\mathrm{ab}}$ & $0.63 \pm 0.10^{\mathrm{a}}$ & $73.25 \pm 6.39^{\mathrm{a}}$ \\
\hline Mondego (AW) & $45.25 \pm 5.08^{\mathrm{ab}}$ & $10.29 \pm 1.71^{\mathrm{a}}$ & $3.98 \pm 0.33^{\mathrm{a}}$ & $14.13 \pm 0.95^{\mathrm{a}}$ & $0.01 \pm 0.03^{\mathrm{ab}}$ & $0.33 \pm 0.83^{\mathrm{a}}$ & $0.55 \pm 0.10^{\mathrm{a}}$ & $74.54 \pm 6.54^{\mathrm{a}}$ \\
\hline Douro (SS) & $48.52 \pm 5.36^{\mathrm{ab}}$ & $16.90 \pm 2.64^{b}$ & $4.28 \pm 0.53^{\mathrm{a}}$ & $15.15 \pm 1.15^{\mathrm{a}}$ & $0.02 \pm 0.02^{\mathrm{ab}}$ & $0.31 \pm 0.74^{\mathrm{a}}$ & $0.60 \pm 0.15^{\mathrm{a}}$ & $85.77 \pm 7.77^{\mathrm{a}}$ \\
\hline Douro (AW) & $67.53 \pm 5.77^{\mathrm{c}}$ & $16.27 \pm 1.54^{\mathrm{b}}$ & $8.23 \pm 0.41^{\mathrm{b}}$ & $25.08 \pm 2.12^{b}$ & $0.03 \pm 0.01^{\mathrm{a}}$ & $0.39 \pm 0.12^{\mathrm{a}}$ & $1.96 \pm 0.53^{\mathrm{b}}$ & $119.49 \pm 8.75^{\mathrm{b}}$ \\
\hline Ave (SS) & $54.43 \pm 4.00^{\mathrm{bc}}$ & $13.04 \pm 0.90^{\mathrm{ab}}$ & $8.59 \pm 1.02^{\mathrm{b}}$ & $32.67 \pm 2.57^{\mathrm{b}}$ & $0.10 \pm 0.03^{\mathrm{b}}$ & $0.64 \pm 0.12^{\mathrm{ab}}$ & $2.40 \pm 0.32^{\mathrm{b}}$ & $111.85 \pm 5.69^{b}$ \\
\hline Ave (AW) & $49.85 \pm 5.70^{\mathrm{ab}}$ & $12.96 \pm 1.05^{\mathrm{ab}}$ & $7.41 \pm 0.79^{\mathrm{b}}$ & $30.16 \pm 4.04^{\mathrm{b}}$ & $0.24 \pm 0.06^{\mathrm{c}}$ & $0.90 \pm 0.23^{\mathrm{b}}$ & $1.99 \pm 0.46^{\mathrm{b}}$ & $103.51 \pm 7.27^{b}$ \\
\hline
\end{tabular}

Data given as mean \pm standard error (average $n=42$ fish/season). Values bearing at least one different superscript letters differ significantly ( $p<0.05$ )

$S S$ spring-summer; $A W$ autumn-winter, $P M$ polymorphic, $S M$ segmented, $K N$ kidney shaped, $B L N$ blebbed/lobed/notched, $B N$ binucleated, $M N$ micronucleus, $V C$ vacuolated

(both in SS and AW) and the Douro (only in relation to AW, but with the SS value clearly showing a midway trend towards an higher number than that seen at the Mondego).

Considering each type of ENMA, the fish from the Mondego tended to exhibit lower values, whatever the season, except for the cases of the BN and MN, which, overall, displayed similar values in both the Mondego and Douro. Still without looking at seasons, the Mondego and Ave fish significantly differed not only in total ENMAs but also in PM and BLN. As to fish from the Ave, the final numbers were always significantly higher than those from the Mondego, and in addition often higher than those from the Douro. Looking at the data in more detail, the differences between the Mondego and the Douro occurred essentially in AW. As to the Ave, and now considering seasons, the local fish consistently had significantly higher values, particularly in AW, both in relation to the Mondego and to the Douro. For most of the particular ENMAs, there were no significant differences between seasons, but when such few differences existed the fish from AW always presented higher values than those from SS. Only in fish from the Douro did the total ENMAs differ significantly between the seasons, being highest in AW.

Finally, as to the MN, the most striking result was the fact that if we take all data together the fish from the Mondego and Douro mullets had a similar frequency, which was significantly lower than that in the Ave. Within each estuary, there were no significant seasonal differences as to the $\mathrm{MN}$ rates.

\section{Water data}

Water physicochemical parameters are displayed in Table 3. When searching for global patterns that could match, or at least follow the same general trends of the ENMAs frequencies, none of the parameters did it unequivocally. Anyway, the average loads both of nitrate and phosphate were (two to three times) were greater in the Ave. As to consistent data trends, the most obvious aspect is the expected lowering of temperature in AW. No hypoxic conditions occurred; oxygen levels and \% saturation were quite ordinary.

Table 3 Water physicochemical parameters for the Mondego, Douro and Ave estuaries, at each season

\begin{tabular}{|c|c|c|c|c|c|c|}
\hline & Mondego (SS) & Mondego (AW) & Douro (SS) & Douro (AW) & Ave (SS) & Ave (AW) \\
\hline $\mathrm{pH}$ & $8.0 \pm 0.1$ & $7.9 \pm 0.1$ & $7.7 \pm 0.1$ & $7.8 \pm 0.1$ & $7.9 \pm 0.8$ & $7.8 \pm 0.8$ \\
\hline Temperature $\left({ }^{\circ} \mathrm{C}\right)$ & $19.0 \pm 0.8$ & $13.4 \pm 0.3$ & $21.8 \pm 0.7$ & $12.7 \pm 0.8$ & $19.6 \pm 1.9$ & $13.3 \pm 0.2$ \\
\hline Salinity & $10.7 \pm 2.4$ & $4.4 \pm 1.7$ & $7.5 \pm 2.3$ & $10.0 \pm 2.1$ & $9.6 \pm 2.1$ & $11.1 \pm 2.0$ \\
\hline Conductivity $(\mathrm{mS} / \mathrm{cm})$ & $18.4 \pm 3.5$ & $8.7 \pm 2.8$ & $11.1 \pm 3.6$ & $14.9 \pm 3.2$ & $15.0 \pm 3.4$ & $14.5 \pm 3.1$ \\
\hline $\mathrm{O}_{2}$ dissolved (mg/L) & $8.3 \pm 0.3$ & $8.9 \pm 0.4$ & $8.6 \pm 0.3$ & $10.0 \pm 0.8$ & $9.0 \pm 0.2$ & $8.8 \pm 0.5$ \\
\hline $\mathrm{O}_{2}$ saturation $(\%)$ & $93.0 \pm 1.8$ & $85.4 \pm 2.7$ & $95.5 \pm 3.2$ & $88.6 \pm 3.3$ & $92.8 \pm 2.9$ & $83.9 \pm 0.6$ \\
\hline Nitrite $(\mathrm{mg} / \mathrm{L})$ & $0.1 \pm 0.0$ & $0.1 \pm 0.0$ & $0.3 \pm 0.2$ & $0.2 \pm 0.1$ & $0.3 \pm 0.1$ & $0.1 \pm 0.0$ \\
\hline Nitrate (mg/L) & $1.2 \pm 0.2$ & $1.4 \pm 0.1$ & $0.5 \pm 0.1$ & $0.5 \pm 0.1$ & $2.3 \pm 0.4$ & $3.7 \pm 0.3$ \\
\hline Total ammonia $(\mathrm{mg} / \mathrm{L})$ & $0.2 \pm 0.0$ & $0.4 \pm 0.1$ & $0.5 \pm 0.2$ & $0.6 \pm 0.3$ & $0.2 \pm 0.1$ & $0.4 \pm 0.1$ \\
\hline Phosphate (mg/L) & $1.1 \pm 0.3$ & $0.6 \pm 0.1$ & $0.9 \pm 0.2$ & $0.9 \pm 0.2$ & $2.5 \pm 0.2$ & $2.5 \pm 0.2$ \\
\hline
\end{tabular}

Data given as mean \pm standard error (average $n=16$ samples/season)

$S S$ spring-summer, $A W$ autumn-winter 


\section{Discussion}

The first aim of this study was the characterization of the morphological types and frequencies of ENMAs in mullets from the Portuguese estuaries of the Mondego, Douro and Ave rivers. The aim was achieved for mullets from the three estuaries, which displayed all types of the reported nuclear changes. These often appeared with different frequencies. All types of diagnosed ENMAs (including $\mathrm{MN}$ ) were earlier described in the literature. However, it was not detected in the samples a condition usually designated as "fragmented nuclei". As mentioned in the "Introduction", the way researchers have been grouping particular ENMAs differs among studies, including those related with fish and environmental monitoring. Herein, it was made an effort to report each type of ENMA individually, which induces a longer time of analysis but potentially provides a more refined approach. For practical reasons, the only grouping made was that referred as BLN. It is emphasized that this kind of strategy and grouping was also followed by other authors, including those using fish (e.g. Gökalp Muranli and Güner 2011; StrunjakPerovic et al. 2009). The diagnosing criteria for every ENMA under analysis is often either not well explained, or adequately and unequivocally illustrated (except for micronuclei), at least in literature with fish, and that is why we included herein a schematic illustration of each considered category (Fig. 2). We think that our approach serves well the research area in terms of better clarifying the several ENMAs at stake, as it offers, for the first time, a practical user-friendly illustration standards that complement the information presented in some "classic" articles (e.g. Al-Sabti and Metcalfe 1995; Bolognesi et al. 2006; Carrasco et al. 1990).

Very few field studies were done in Portuguese estuaries looking at genotoxic biomarkers in fish species, either by sampling wild animals or making in situ exposures (Costa et al. 2011; Oliveira et al. 2010; Guilherme et al. 2008; Maria et al. 2006; Pacheco and Santos 1999). Most of the studies targeted the Aveiro (Aveiro lagoon) and Lisbon regions (Tagus and Sado estuaries). The Mondego, Douro and Ave estuaries lacked such kind of approach. So, despite the more recent efforts, little information is presently available to help mapping and monitoring genotoxic exposure in such ecosystems, namely by looking at the occurrence of those kinds of biomarkers at a particular time, and then following their progress with time. The analysis of ENMAs is particularly interesting for the latter case (i.e. monitoring over time), not only by the reasons already cited in the Introduction, but also for the real potential of sampling only the blood in the field without actually killing the animals. Though, and as a starting point for evaluating the three ecosystems, individuals were sacrificed because they served varied working purposes.

As to the total number of ENMAs, the values were lower in the Mondego and equally higher in the Douro and Ave, with mean frequencies of $\approx 73 \%$, in the former, and $\approx 101$ and 108 $\%$ in the latter. Concerning field studies, authors have been considering different combinations of ENMAs to compute total frequencies. By caution, we will not directly compare herein our total values with those from other studies. The important here is that this data on the total ENMAs suggested a scenario of greater exposure to genotoxic contamination in the Douro and Ave estuaries. Other field surveys that used total ENMAs to access such type of contamination support our view (no matter what combination of nuclear abnormalities was ultimately included in the total counts) (Cavalcante et al. 2008; Van Ngan et al. 2007).

The analysis of the MN partially corroborated the pattern offered by the total ENMAs, since the mullets from the Mondego and Douro had similar frequencies of MN, and those from the Ave had significantly higher rate of the lesion; on average $0.75 \%$. Thus, these data supports the hypothesis
Fig. 2 Realistic representation of the different kind of erythrocytes nuclear morphological abnormalities (ENMAs) considered in this study and that could serve as a practical guide for other field surveys

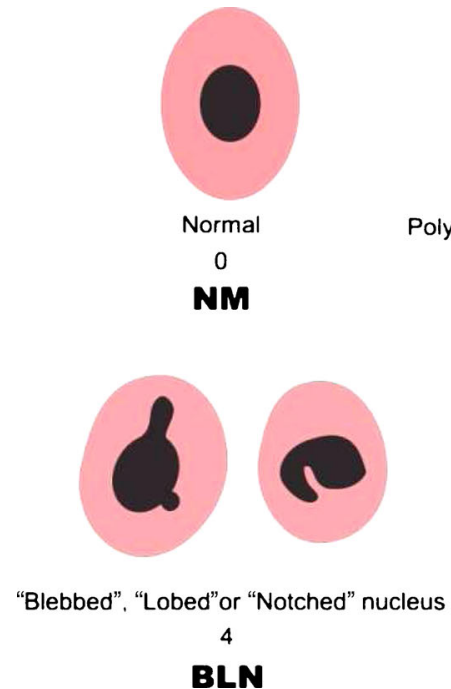

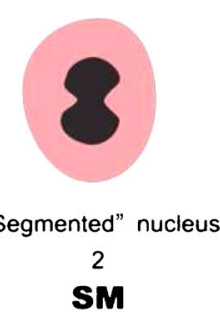

PM

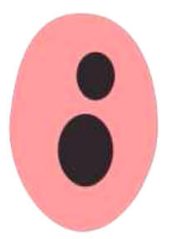

Binucleated 5
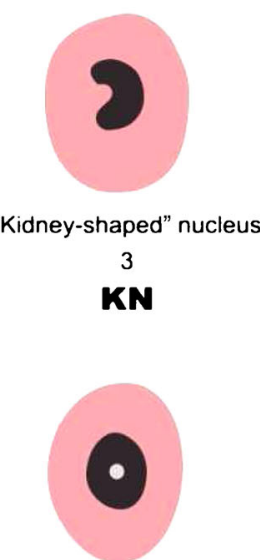

"Vacuolated" nucleus 7 
that the latter estuary was more impacted by pollution with genotoxicants. Good studies were published supporting this kind of environmental inference. For example, Minissi et al. (1996) noted a higher rate of MN in fish caught in the polluted river Tiber (Italy), $\approx 0.32 \%$, when compared to fish (Barbus plebejus) both from the Mignone river (inside an unpolluted natural reserve), with $\approx 0.15 \%$, and from in-house produced controls, with $\approx 0.05 \%$. In the same vein, Porto et al. (2005) found much higher frequencies of $\mathrm{MN}$ in three species from different trophic levels from the Madeira river (a mercury polluted system), averaging $\approx 0.4$ to $1.8 \%$, compared to baseline rates (of $\approx 0.01 \%$ ) for the same species from an unpolluted area of the Solimões River. Equally, in a study by Rybakovas et al. (2009), the frequencies of $\mathrm{MN}$ were higher than the reference values $(<0.05$ and $<0.1 \%$ depending on location), and up to 0.5 $\%$, in two flatfishes (Platichthys flesus and Limanda limanda) from areas close to oil and gas platforms in the North Sea, and in zones related to extensive shipping and affected by contamination from large European Rivers (Elbe, Vistula and Oder). Finally, we must refer a study that also targeted the grey mullet as bioindicator, which showed that the frequencies of several ENMAs (including $\mathrm{MN}$ ) in erythrocytes from polluted areas in the southeastern Mediterranean coast of Turkey were significantly higher than those from one reference zone (Çavas and Ergene-Gözükara 2005b). Overall, if only MN were analysed in our study, we could theorize, with a reasonable likelihood of certainty, that the Ave estuary was being more impacted with genotoxic compounds. However, only looking at other ENMAs, we could refine the relative pollution status of the Douro estuary; this further strengthens the interest of looking at further ENMAs rather than solely the MN.

It is opportune to mention that despite in the above-cited environmental studies the frequencies of $\mathrm{MN}$ were within the ranges got in the present study, there must be caution when interpreting the data exact meaning facing the difficulty in establishing sound reference values for supporting generalizations. So, conclusions must be essentially based on comparative reasoning on diversely affected scenarios rather than on just looking at single cases. Accordingly, we should not conclude by solely looking at the MN rates that either the Mondego or the Douro estuaries would not be impacted at all by genotoxicants. On the contrary, because frequencies of $\mathrm{MN}>0.3 \%$ (in fish erythrocytes) usually reflect genotoxic polluted ecosystems. Moreover, surveys under contamination gradients may actually reveal alleged reference values (including for mullets) that are much higher than those found in the present work. For example, in a study made in the Goksu Delta (Turkey), grey mullets from the reference areas (upstream of the polluted zones) had an average MN rate of $1.26 \%$; the value rose to up an impressive $3.86 \%$ in the considered polluted areas (Ergene et al. 2007). A similar trend was found also in grey mullets, but now from the Saronikos Gulf, Greece (Tsangaris et al. 2011). The above considerations also apply to all the other ENMAs, and therefore warn that significantly lower values of a particular ENMA in a supposedly less polluted area should not be simplistic viewed as synonymous of having an environment that is free from genotoxicity.

To help interpreting the inferences between the presence of ENMAs (including MN) and the presumed local ongoing pollution by genotoxicants, one further aspect we want to emphasize concerns the question of an eventual lag between the contact of the fish with chemicals and the surge of ENMAs. Experimental data have been consistently proving that $\mathrm{MN}$ and other abnormalities appear very rapidly after such exposures. For instance, in an experiment undertaken with two species of cichlids (Palhares and Grisolia 2002), it was verified that fish injected intra-abdominally with either cyclophosphamide or mitomycin $\mathrm{C}$ significantly raised the $\mathrm{MN}$ rates in erythrocytes within 1 day. Studies with common water pollutants have corroborated those with reference genotoxicants, as in the case of a waterborne assay with an atrazine-based herbicide, which evoked $\mathrm{MN}$ in erythrocytes on the goldfish (Carassius auratus) in just 2 days (Cavas 2011). On the other hand, withdrawal of genotoxicant exposure may also result on the decrease of ENMAs, as shown for example in an experiment with the rainbow trout (Oncorhynchus mykiss), in which after just a 96-h recovery in clean water the rate of MN decreased (Bagdonas and Vosyliene 2006). Decline of ENMAs after removing exposures can actually continue over a wide period. For instance, Minissi et al. (1996) noted that both at 50 and 100 days after capture, barbels (Barbus plebejus) experienced a marked decrease in $\mathrm{MN}$ when compared with the rate at the time of capture. All the above implies that the presence of ENMAs in fish captured at any particular environment very likely indicates that the ecosystem was being impacted by genotoxicants, or at least that it was recently polluted. Also, finding relevant levels of ENMAs on different timings very possibly denotes that the ecosystem in question was frequently - or even permanently - polluted with those kinds of chemicals. In this context, the catadromous nature of mullets as mentioned in "Materials and methods" should not influence the ENMAs frequencies.

With the above in mind, an aspect worth addressing is the fact that our data were, overall, quite stable between the two analysed seasons, and seasonal differences existed essentially in the Douro: with fish from AW showing higher values in four out of the five types ENMAs (but not in MN) and also in the total ENMAs. Chemical monitoring studies in the Douro estuary showed that seasonal fluctuations exist for certain water pollutants, some of them having higher amounts in the winter whereas other prevail in summer (Ribeiro et al. 2009b; Rocha et al. 2012b). In view of this, we can hypothesize that 
the type and amount of pollutants appearing at particular seasons is likely the cause of the ENMAs seasonality, but we cannot advance a unique and indisputable explanation for the stability versus variability of the rates. In support of our version is the fact that Çavas and Ergene-Gözükara (2005b), also studying grey mullets, found seasonal differences in MN rates in the zones but not in the reference (less polluted) area. So, the most central message in our study is that whatever the season, ENMAs existed and in relevant rates, which strengthens conclusions about the presence of genotoxicants in the estuaries, and that such pollution should not be a random event, but it was (and likely is) frequent. The existence of seasonal variations in the rate of ENMAs is not unprecedented, but it is still largely underexplored. When evaluating the seasonality of ENMAs in the gilthead sea bream (Sparus aurata), Strunjak-Perovic et al. (2009) concluded with the hypothesis that ENMAs may originate from genetic disorders not necessarily connected with pollutants, and that the expression of those non-pollution-related ENMAs may depend on environmental conditions.

As to the interplay of biotic and abiotic factors on the formation of MN and other ENMAs, we know, for instance, that hypoxia induced $\mathrm{MN}$ in mice erythrocytes (Snyder and Diehl 2005), but this is not inevitably the case for fish, as shown in the slender seahorse (Hippocampus reidi) (Negreiros et al. 2011). Recent reviews addressed the molecular mechanisms and factors that may lead to the formation of $\mathrm{MN}$ and other nuclear anomalies, in view of their accepted value as biomarkers of genotoxic events and of chromosomal instability (Bolognesi and Hayashi 2011; Fenech and Bonassi 2011; Fenech et al. 2011). These reviews pointed the knowledge many gaps in understanding those mechanisms, while stressing that the formation of ENMAs is sensitive to deficiencies of nutrients that are needed for genome maintenance, and that, at least for humans, age, gender, and lifestyle play a role; for aquatic animals, $\mathrm{pH}$, salinity and temperature seem to influence, with higher temperature favouring emergence of MN (by increasing the mitotic rates). Considering that understanding the fine impacts of such influences in fish ENMAs is currently scanty and that in biomonitoring it is virtually impossible to control all the possible factors that could influence the data, these should always be interpreted as much as possible in the light of additional retrospective or prospective information, namely from chemistry, and from awareness of the relevant pollution sources. Our present data seems primarily connected with pollutants, considering that: (1) our baseline biological samples were matched among estuaries, namely concerning fish mass and size; (2) no hypoxic conditions existed; (3) other abiotic factors did not reach extremes, and particularly nitrites (potentially highly toxic for fish) were fairly constant across estuaries; (5) the seasonal cycles of temperature did not logically correlate at all with the variation patterns of any of the ENMAs; (6) the fairly high values of nitrate (and sum nitrite-nitrate) and phosphate in the Ave (despite not per se in extremes that could be viewed as stressful for fish) suggest there is more pollution in that ecosystem (Chapman 1992); (7) finally, all the chemical surveys published for all the three studied estuaries - and that we cited throughoutconcur with our inferences.

As well acknowledged by Çavas and Ergene-Gözükara (2005b), "an inherent weakness of an in situ study using wild fish is the lack of a true negative control", and so the interpretations must take into account the data and conclusions from previous or parallel studies, namely those that provide indications of the relative levels of pollutants at the sampling sites. We conducted this approach in our present study. Facing the lack of in-depth knowledge for every Portuguese estuary, namely based on solid gold-standard chemistry - that have been progressing in parallel with biomarker studies-we could not initially pinpoint an indisputable reference for our aims. We are investigating other estuaries (namely those of the Lima and Minho rivers), to in time establish a superior reference scenario for future studies looking at ENMAs in mullet; our pilot data for the Lima estuary (unpublished) suggest MNs rates alike those of the Mondego. There are no data for the Minho, also already used as reference in ecotoxicology (Gravato et al. 2010).

Overall, this study showed that ENMAs existed in fish from all three estuaries, with the rates of the abnormalities suggesting that genotoxicants exposure and impacts were increasingly existent from the Mondego, towards the Douro and finally the Ave. These results are indeed in line with our expectations, despite warning that the supposedly less polluted Mondego (sometimes used as a reference estuary) may be still subjected to biologically relevant impacts of genotoxic pollution. The current data nicely agrees with conclusions drawn from the same fish, using the presence of ovotestis as a biomarker of pollution by endocrine disrupting compounds (Carrola 2011). Preliminary data on liver lesions also exposed similar spatial trends (Carrola 2011). Overall, our biomarker data (despite potentially related with different kind of pollutants) clearly point to an increasing global pollution load from the Mondego towards the Ave. Further supporting this inference, recent studies disclosed the presence of significant water and sediment loads of well-known genotoxicants (pesticides and polycyclic aromatic hydrocarbons) in the Douro and nearby Porto costal region (Rocha et al. 2011, 2012b). Also, and globally, the latest chemical screenings in the Mondego, Douro and Ave estuaries, particularly those covering estrogenic compounds (Ribeiro et al 2009a, b; Rocha et al 2011, 2012b, 2013a, b), do support our hypothesis of a growingly worst pollution scenario, and increasing biological/ genotoxicity impacts on fish, from the Mondego towards the Ave. 


\section{Conclusions}

Using the mullet as a bioindicator, a diversity of ENMAs was found in the fish from the estuaries of the Mondego, Douro and Ave Rivers. The total average frequency of the nuclear abnormalities ranged from $73 \%$ in the Mondego to $108 \%$ in the Ave. The ENMAs found were divided as follows: PM, $\mathrm{SM}, \mathrm{KN}, \mathrm{BLN}, \mathrm{BN}, \mathrm{MN}$ and VC. The more emblematic biomarker of ongoing genotoxicity (MN) displayed an average frequency of 0.41 and of $0.35 \%$, in the Mondego and Douro fish, respectively, and a significantly higher rate of $0.75 \%$ in the Ave mullets. Considering the data for both the total ENMAs and for each specific nuclear abnormality, we concluded that the fish were being exposed to genotoxicants all throughout the year-most likely even in the reportedly cleaner ecosystem (the Mondego estuary) - and that such exposure followed a severity gradient towards the Ave (Mondego $<$ Douro $<$ Ave). Importantly, the new data sets can be used as baselines against which the results from future biomonitoring studies can be compared with.

Acknowledgments This work was partially supported by the European Regional Development Fund (ERDF) funds through the Competitiveness and Trade Expansion Program (COMPETE), and by National Funds provided by Fundação para a Ciência e a Tecnologia (FCT), via the research projects PTDC/MAR/70436/2006, PEst-C/MAR/LA0015/ 2011, PEst-C/MAR/LA0015/2013, and also by the PhD grant SFRH/BD/25746/2005.

\section{References}

Al-Sabti K, Hardig J (1990) Micronucleus test in fish for monitoring the genotoxic effects of industrial waste products in the Baltic Sea, Sweden. Comp Biochem Physiol C Comp Pharmacol 97:179-182

Al-Sabti K, Metcalfe CD (1995) Fish micronuclei for assessing genotoxicity in water. Mutat Res/Genet Toxicol 343:121-135

Arslan ZÇ, Parlak H, Katalay S, Boyacioglu M, Karaaslan MA, Guner H (2010) Detecting micronuclei frequency in some aquatic organisms for monitoring pollution of Izmir Bay (Western Turkey). Environ Monit Assess 165:55-66

Ayllon F, Garcia-Vazquez E (2000) Induction of micronuclei and other nuclear abnormalities in European minnow Phoxinus phoxinus and mollie Poecilia latipinna: an assessment of the fish micronucleus test. Mutat Res/Genet Toxicol Environ Mutagen 467:177-186

Ayllón F, Garcia-Vazquez E (2001) Micronuclei and other nuclear lesions as genotoxicity indicators in rainbow trout Oncorhynchus mykiss. Ecotoxicol Environ Saf 49:221-225

Bagdonas E, Vosylienè MZ (2006) A study of toxicity and genotoxicity of copper, zinc and their mixture to rainbow trout (Oncorhynchus mykiss). Biologija 1:8-13

Barsiene J, Dedonyte V, Rybakovas A, Andreikenaite L, Andersen OK (2006) Investigation of micronuclei and other nuclear abnormalities in peripheral blood and kidney of marine fish treated with crude oil. Aquat Toxicol 78:S99-S104

Baršienė J, Rybakovas A, Lang T, Grygiel W, Andreikènaitė L, Michailovas A (2012) Risk of environmental genotoxicity in the Baltic Sea over the period of 2009-2011 assessed by micronuclei frequencies in blood erythrocytes of flounder (Platichthys flesus), herring (Clupea harengus) and eelpout (Zoarces viviparus). Mar Environ Res 77:35-42

Bartulović V, Dulčić J, Matić-Skoko S, Glamuzina B (2011) Reproductive cycles of Mugil cephalus, Liza ramada and Liza aurata (Teleostei: Mugilidae). J Fish Biol 78:2067-2073

Bolognesi C, Hayashi M (2011) Micronucleus assay in aquatic animals. Mutagenesis 26:205-213

Bolognesi C, Perrone E, Roggieri P, Pampanin DM, Sciutto A (2006) Assessment of micronuclei induction in peripheral erythrocytes of fish exposed to xenobiotics under controlled conditions. Aquat Toxicol 78:S93-S98

Blaber SJM (1976) The food and feeding ecology of Mugilidae in the St. Lucia lake systems. Biol J Linn Soc 8:267-277

Buschini A, Martino A, Gustavino B, Monfrinotti M, Poli P, Rossi C, Santoro M, Dörr AJM, Rizzoni M (2004) Comet assay and micronucleus test in circulating erythrocytes of Cyprinus carpio specimens exposed in situ to lake waters treated with disinfectants for potabilization. Mutat Res/Genet Toxicol Environ Mutagen 557: 119-129

Chapman D (1992) Water quality assessments. Chapman and Hall, London

Cardona L (2006) Habitat selection by grey mullets (Osteichthyes: Mugilidae) in Mediterranean estuaries: the role of salinity. Sci Mar 70:443-455

Carrasco KR, Tilbury KL, Myers MS (1990) Assessment of the piscine micronucleus test as an insitu biological indicator of chemical contaminant effects. Can J Fish Aquat Sci 47:2123-2136

Carrola J (2011) Light microscopic studies of toxicopathic changes in fishes from the Tinhela and Vizela rivers, and from the Mondego, Douro and Ave estuaries. Dissertation. Universidade de Trás-osMontes e Alto Douro, Portugal.

Carvalho PN, Rodrigues PNR, Basto MCP, Vasconcelos MTSD (2009) Organochlorine pesticides levels in Portuguese coastal areas. Chemosphere 75:595-600

Cavalcante DGSM, Martinez CBR, Sofia SH (2008) Genotoxic effects of Roundup ${ }^{\circledR}$ on the fish Prochilodus lineatus. Mutat Res/Genet Toxicol Environ Mutagen 655:41-46

Cavas T (2011) In vivo genotoxicity evaluation of atrazine and atrazinebased herbicide on fish Carassius auratus using the micronucleus test and the comet assay. Food Chem Toxicol 49:1431-1435

Çavas T, Ergene-Gözükara S (2005a) Induction of micronuclei and nuclear abnormalities in Oreochromis niloticus following exposure to petroleum refinery and chromium processing plant effluents. Aquat Toxicol 74:264-271

Çavas T, Ergene-Gözükara S (2005b) Micronucleus test in fish cells: a bioassay for in situ monitoring of genotoxic pollution in the marine environment. Environ Mol Mutagenicity 46:64-70

Cavas T, Garanko NN, Arkhipchuk VV (2005) Induction of micronuclei and binuclei in blood, gill and liver cells of fishes subchronically exposed to cadmium chloride and copper sulphate. Food Chem Toxicol 43:569-574

Cardoso PG, Lillebø AI, Pereira E, Duarte AC, Pardal MA (2009) Different mercury bioaccumulation kinetics by two macrobenthic species: the bivalve Scrobicularia plana and the polychaete Hediste diversicolor. Mar Environ Res 68:12-18

Costa C, Silva S, Coelho P, Roma-Torres J, Teixeira JP, Mayan O (2007) Micronucleus analysis in a Portuguese population exposed to pesticides: preliminary survey. Int J Hyg Environ Health 210:415-418

Costa PM, Caeiro S, Lobo J, Martins M, Ferreira AM, Caetano M, Vale C, DelValls TÁ, Costa MH (2011) Estuarine ecological risk based on hepatic histopathological indices from laboratory and in situ tested fish. Mar Pollut Bull 62:55-65

CostaEiras JD, Carraca S (1979) Note on the biology of Mugil cephalus (L) in northern Portugal-yearly variations in weight-length ratios, hepatosomatic ratios, and coefficients of condition. Nat Can 106: 415-419 
Da Rocha CAM, De Lima PDL, Dos Santos RA, Burbano RMR (2009) The micronucleus assay in fish species as an important tool for xenobiotic exposure risk assessment - a brief review and an example using neotropical fish exposed to methylmercury. Rev Fish Sci $17: 478-484$

Da Silva ST, Fontanetti CS (2006) Micronucleus test and observation of nuclear alterations in erythrocytes of Nile tilapia exposed to waters affected by refinery effluent. Mutat Res Genet Toxicol Environ Mutagen 605:87-93

De Flora S, Vigano L, D'Agostini F, Camoirano A, Bagnasco M, Bennicelli C, Melodia F, Arillo A (1993) Multiple genotoxicity biomarkers in fish exposed in situ to polluted river water. Mutat Res 319:167-177

Díez S, Lacorte S, Viana P, Barceló D, Bayona JM (2005) Survey of organotin compounds in rivers and coastal environments in Portugal 1999-2000. Environ Pollut 136:525-536

Ergene S, Çavaș T, Çelik A, Köleli N, Kaya F, Karahan A (2007) Monitoring of nuclear abnormalities in peripheral erythrocytes of three fish species from the Göksu Delta (Turkey): genotoxic damage in relation to water pollution. Ecotoxicology 16:385-391

Fenech M, Bonassi S (2011) The effect of age, gender, diet and lifestyle on DNA damage measured using micronucleus frequency in human peripheral blood lymphocytes. Mutagenesis 26:43-49

Fenech M, Kirsch-Volders M, Natarajan AT, Surralles J, Crott JW, Parry J, Norppa H, Eastmond DA, Tucker JD, Thomas P (2011) Molecular mechanisms of micronucleus, nucleoplasmic bridge and nuclear bud formation in mammalian and human cells. Mutagenesis 26:125-132

Gökalp Muranli FD, Güner U (2011) Induction of micronuclei and nuclear abnormalities in erythrocytes of mosquito fish (Gambusia affinis) following exposure to the pyrethroid insecticide lambdacyhalothrin. Mutat Res Genet Toxicol Environ Mutagen 726:104 108

Gravato C, Guimarães L, Santos J, Faria M, Alves A, Guilhermino L (2010) Comparative study about the effects of pollution on glass and yellow eels (Anguilla anguilla) from the estuaries of Minho, Lima and Douro Rivers (NW Portugal). Ecotoxicol Environ Saf 73:524 533

Guilherme S, Válega M, Pereira ME, Santos MA, Pacheco M (2008) Erythrocytic nuclear abnormalities in wild and caged fish (Liza aurata) along an environmental mercury contamination gradient. Ecotoxicol Environ Saf 70:411-421

Gundersen HJG (1977) Notes on the estimation of the numerical density of arbitrary profiles: the edge effect. J Microsc 111:219-223

Hooftman RN, de Raat WK (1982) Induction of nuclear anomalies (micronuclei) in the peripheral blood erythrocytes of the eastern mudminnow Umbra pygmaea by ethyl methanesulphonate. Mutat Res Lett 104:147-152

Hose JE, Cross JN, Smith SG, Diehl D (1987) Elevated circulating erythrocyte micronuclei in fishes from contaminated sites off Southern California. Mar Environ Res 22:167-176

Madureira TV, Barreiro JC, Rocha MJ, Cass QB, Tiritan ME (2009) Pharmaceutical trace analysis in aqueous environmental matrices by liquid chromatography-ion trap tandem mass spectrometry. J Chromatogr A 1216:7033-7042

Madureira TV, Barreiro JC, Rocha MJ, Rocha E, Cass QB, Tiritan ME (2010) Spatiotemporal distribution of pharmaceuticals in the Douro River estuary (Portugal). Sci Total Environ 408:5513-5520

Maria VL, Pacheco M, Santos MA (2006) Anguilla anguilla L. Genotoxic responses after in situ exposure to freshwater wetland (Pateira de Fermentelos, Portugal). Environ Int 32:510-515

Minissi S, Ciccotti E, Rizzoni M (1996) Micronucleus test in erythrocytes of Barbus plebejus (Teleostei, Pisces) from two natural environments: a bioassay for the in situ detection of mutagens in freshwater. Mutat Res Genet Toxicol 367:245-251

Mitchelmore CL, Chipman JK (1998) DNA strand breakage in aquatic organisms and the potential value of the comet assay in environmental monitoring. Mutat Res Fundam Mol Mech Mutagen 399:135-147

Negreiros LA, Silva BF, Paulino MG, Fernandes MN, Chippari-Gomes AR (2011) Effects of hypoxia and petroleum on the genotoxic and morphological parameters of Hippocampus reidi. Comp Biochem Physiol Toxicol Pharmacol 153:408-414

Oates L, Cohen M (2009) Human consumption of agricultural toxicants from organic and conventional food. J Org Syst 4:48-57

Oliveira M, Maria VL, Ahmad I, Pacheco M, Santos MA (2010) Seasonal Liza aurata tissue-specific DNA integrity in a multi-contaminated coastal lagoon (Ria de Aveiro, Portugal). Mar Pollut Bull 60:17551761

Oren OH (1981) Aquaculture of grey mullets. Part of International Biological Programme Synthesis Series (Book 26). Cambridge University Press, Cambridge

Pacheco M, Santos MA (1999) Biochemical and genotoxic responses of adult eel (Anguilla anguilla L.) to resin acids and pulp mill effluent: laboratory and field experiments. Ecotoxicol Environ Saf 42:81-93

Palhares D, Grisolia CK (2002) Comparison between the micronucleus frequencies of kidney and gill erythrocytes in tilapia fish, following mitomycin C treatment. Genet Mol Biol 25:281-284

Porto JI, Araujo CS, Feldberg E (2005) Mutagenic effects of mercury pollution as revealed by micronucleus test on three Amazonian fish species. Environ Res 97:287-292

Ramalhosa E, Pereira E, Vale C, Válega M, Monterroso P, Duarte AC (2005) Mercury distribution in Douro estuary (Portugal). Mar Pollut Bull 50:1218-1222

Ribeiro C, Pardal MA, Martinho F, Margalho R, Tiritan ME, Rocha E, Rocha MJ (2009a) Distribution of endocrine disruptors in the Mondego River estuary, Portugal. Environ Monit Assess 149:183-193

Ribeiro C, Tiritan ME, Rocha E, Rocha MJ (2009b) Seasonal and spatial distribution of several endocrine-disrupting compounds in the Douro River Estuary, Portugal. Arch Environ Contam Toxicol 56:1-11

Rocha MJ, Ferreira P, Reis A, Cruzeiro C, Rocha E (2011) Development and validation of a MAE-SPE-GC-MS method for the evaluation of sixteen priority polycyclic aromatic hydrocarbons in marine and estuarine sediments - applications to the Porto coastal region (Portugal). J Chromatogr Sci 49:695-701

Rocha MJ, Ribeiro M, Cruzeiro C, Figueiredo F, Rocha E (2012a) Development and validation of a GC-MS method for determination of 39 common pesticides in estuarine water - targeting hazardous amounts in the Douro River estuary. Int J Environ Anal Chem 92:1587-1608

Rocha MJ, Cruzeiro C, Ferreira C, Rocha E (2012b) Occurrence of endocrine disruptor compounds in the estuary of the Iberian Douro River and nearby Porto Coast (NW Portugal). Toxicol Environ Chem 94:252-261

Rocha MJ, Cruzeiro C, Rocha E (2013a) Quantification of 17 endocrine disruptor compounds and their spatial and seasonal distribution in the Iberian Ave River and its coastline. Toxicol Environ Chem 95:386-399

Rocha MJ, Cruzeiro C, Rocha E (2013b) Development and validation of a GC-MS method for the evaluation of 17 endocrine disruptor compounds, including phytoestrogens and sitosterol, in coastal waters - their spatial and seasonal levels in Porto costal region (Portugal). J Water Health 11:281-296

Rocha PS, Luvizotto GL, Kosmehl T, Bottcher M, Storch V, Braunbeck T, Hollert H (2009) Sediment genotoxicity in the Tiete River (Sao Paulo, Brazil): in vitro comet assay versus in situ micronucleus assay studies. Ecotoxicol Environ Saf 72:1842-1848

Rodriguez-Cea A, Ayllon F, Garcia-Vazquez E (2003) Micronucleus test in freshwater fish species: an evaluation of its sensitivity for application in field surveys. Ecotoxicol Environ Saf 56:442-448

Rybakovas A, Barsiene J, Lang T (2009) Environmental genotoxicity and cytotoxicity in the offshore zones of the Baltic and the North Seas. Mar Environ Res 68:246-256

Saleh MA (2006) Cultured aquatic species information programme. Mugil cephalus. FAO Fisheries and Aquaculture Department. 
http://www.fao.org/fishery/culturedspecies/Mugil_cephalus/en. Accessed 28 Dec 2013

Schlegel R, MacGregor JT (1982) The persistence of micronuclei in peripheral blood erythrocytes: detection of chronic chromosome breakage in mice. Mutat Res Lett 104:367-369

Snyder RD, Diehl MS (2005) Hypoxia-induced micronucleus formation in mice. Drug Chem Toxicol 28:373-378

Speit G, Schmid O (2006) Local genotoxic effects of formaldehyde in humans measured by the micronucleus test with exfoliated epithelial cells. Mutat Res Rev Mutat Res 613:1-9

Strunjak-Perovic I, Coz-Rakovac R, Topic Popovic N, Jadan M (2009) Seasonality of nuclear abnormalities in gilthead sea bream Sparus aurata (L.) erythrocytes. Fish Physiol Biochem 35:287-291

Tijhuis MJ, de Jong N, Pohjola MV, Gunnlaugsdóttir H, Hendriksen M, Hoekstra J, Holm F, Kalogeras N, Leino O, van Leeuwen FX, Luteijn JM, Magnússon SH, Odekerken G, Rompelberg C, Tuomisto JT, Ueland Ø, White BC, Verhagen H (2012) State of the art in benefitrisk analysis: food and nutrition. Food Chem Toxicol 50:5-25

Tsangaris C, Vergolyas M, Fountoulaki E, Nizheradze K (2011) Oxidative stress and genotoxicity biomarker responses in grey mullet (Mugil cephalus) from a polluted environment in Saronikos Gulf, Greece. Arch Environ Contam Toxicol 61:482-490

Van Ngan P, Gomes V, Passos M, Ussami K, Campos D, Rocha A, Pereira B (2007) Biomonitoring of the genotoxic potential (micronucleus and erythrocyte nuclear abnormalities assay) of the Admiralty Bay water surrounding the Brazilian Antarctic Research Station "Comandante Ferraz", King George Island. Polar Biol 30:209-217

Vigano L, Camoirano A, Izzotti A, D’Agostini F, Polesello S, Francisci C, De Flora S (2002) Mutagenicity of sediments along the Po River and genotoxicity biomarkers in fish from polluted areas. Mutat Res Genet Toxicol Environ Mutagen 515:125-134

Whitfield AK, Panfili J, Durand JD (2012) A global review of the cosmopolitan flathead mullet Mugil cephalus Linnaeus 1758 (Teleostei: Mugilidae), with emphasis on the biology, genetics, ecology and fisheries aspects of this apparent species complex. Rev Fish Biol Fish 22:641-681

Winter MJ, Ellis LCJ, Hutchinson TH (2007) Formation of micronuclei in erythrocytes of the fathead minnow (Pimephales promelas) after acute treatment with mitomycin $\mathrm{C}$ or cyclophosphamide. Mutat Res Genet Toxicol Environ Mutagen 629:89-99 